\title{
Caracterização histológica do desenvolvimento hepático em diferentes estágios embrionários de ratos
}

\author{
Histological characterization of the liver development at different embryonic stages of rats
}

\author{
Arthur Cássio de Lima Luna ${ }^{I}$ Cristiane Carlin Passos ${ }^{\text {II }}$ Amanda Olivotti Ferreira ${ }^{\text {II }}$ \\ Maria Angélica Miglino ${ }^{\text {II }}$ Ricardo Romão Guerra ${ }^{I^{*}}$
}

RESUMO

\begin{abstract}
Os ratos apresentam desenvolvimento embrionário similar aos de animais domésticos e humanos, sendo assim um modelo válido para estudos cientificos. Dentre eles, o F344 se destaca por ser uma linhagem isogênica, facilitando a leitura dos resultados obtidos, devido a sua homogeneidade gênica. Devido à falta de estudos histológicos acerca do desenvolvimento hepático em ratos, o presente estudo tem como objetivo caracterizar histologicamente pela primeira vez o processo de desenvolvimento hepático nos estágios embrionários de E12,5 (12,5 dias de gestação), E13,5, E14,5, E15,5 e E16,5 em ratos F344. Cinco embriões de cada estágio embrionário foram coletados, fixados em Metacarn, incluídos em paraplast e realizadas colorações histológicas e histoquímica. Os brotos hepáticos de embriões entre 12,5-14,5 dias apresentaram-se como aglomerados de hepatoblastos, ainda desorganizados e circundados por inúmeras células precursoras sanguineas nucleadas. Observou-se que os hepatoblastos possuem um núcleo grande basofilico com pouco citoplasma. Sinusoides com eritroblastos e células de Kupffer também foram encontrados. Com 14,5 dias, foi observada a coexistência de hepatoblastos e hepatócitos, além de megacariócitos. Nos embriões com 15,5 dias, começou a verificar-se distinção entre os cordões de hepatócitos em formação, limitados pelos capilares sinusoides. Tais cordões começavam a confluir para as presentes veias centrolobulares. Com 16,5 dias, a arquitetura parenquimal estava mais próxima da encontrada em fígados adultos, sendo a quantidade de hepatócitos superior à de hepatoblastos. Nesse prazo gestacional, o figado ainda tinha função hematopoiética. O estudo traz histologicamente o desenvolvimento hepático entre 12,5-16,5 dias de ratos da linhagem F344, evidenciando as células que compóem cada periodo gestacional, gerando subsidios para futuros estudos.
\end{abstract}

Palavras-chave: hepatogênese, hepatócitos, histologia, isogênia.

\section{ABSTRACT}

The rats have embryonic development similar to other domestic animals and human beings, thus a valid model for scientific studies. Among them, the F344 stands out for be isogenic, facilitating the reading of the results obtained because of their genetic homogeneity. Due to the lack of histological studies concerning hepatic development in rats, the present study aimed to characterize histologically for the first time the process of developing liver in the stages of gestation of E12.5 (12.5 days of gestation), E13.5, E14.5, E15.5 and E16.5 in rats F344. Five embryos of each embryonic stage were collected, fixed in Metacarn, embedded in Paraplast and then histological stains and histochemistry were performed. The hepatic bud of embryo among 12.5-14.5 days presented themselves a cluster of hepatoblasts still disorganized and surrounded by numerous nucleated blood precursor cells. It was observed that the hepatoblasts have a large nucleus basophilic with little cytoplasm. Sinusoids with erythroblasts and Kupffer cells also have been found. At 14.5 days it was observed the coexistence of hepatoblasts and hepatocytes. In the embryos with 15.5 days began the verify distinction between the cords of hepatocytes in formation limited by capillary sinusoids. Such cords began to converge for the present centrilobular veins. At 16.5 days the parenchymal architecture was nearer found in the adult liver, being the quantity of hepatocytes greater than hepatoblasts. During this gestation period the liver also had hematopoietic function. The study brings histologically the rats $F 344$ hepatic development between 12.5-16.5 days, evidencing the cells that comprise each gestational period generating subsidies for future studies.

Key words: hepatogenese, hepatocytes, histology, isogenia.

\section{INTRODUÇÃO}

O desenvolvimento embrionário dos vertebrados tem sido o foco de estudos durante muito

IPrograma de Pós-graduação em Ciência Animal (PPGCAn), Centro de Ciências Agrárias (CCA), Universidade Federal da Paraíba (UFPB), Areia, PB, Brasil. E-mail: ricardo@cca.ufpb.br. *Autor para correspondência.

IIPrograma de Pós-graduação em Anatomia dos Animais Domésticos e Silvestres, Faculdade de Medicina Veterinária e Zootecnia (FMVZ), Universidade de São Paulo (USP), São Paulo, SP, Brasil. 
tempo, no entanto, somente nas últimas décadas, o progresso desses estudos tem sido esclarecido (PASSOS, 2010). Apesar desses esclarecimentos, as características histológicas de tais processos continuam sendo uma lacuna, principalmente de órgãos de origem endodérmica com o fígado.

O fígado é o maior órgão interno, fornecendo metabólicos essenciais, exócrino e endócrino. Estes incluem a produção da bile, metabolismo de compostos alimentares, de desintoxicação, a regulação dos níveis de glicose por meio de armazenamento de glicogênio e de controle da homeostase do sangue por secreção de fatores de coagulação e proteínas séricas, tais como a albumina (POUTON \& HAYNES, 2005; ZORN, 2008). O processo de formação do fígado é composto por múltiplos estágios de desenvolvimento, no qual a indução da destinação hepática depende de interações recíprocas entre o endoderma ventral do intestino anterior e o tecido mesenquimal adjacente (ZARET, 2002). Em ratos, o desenvolvimento embrionário é similar ao dos outros vertebrados, tendo o início da gastrulação no oitavo dia de gestação $(\mathrm{E} 8,5)$. A formação dos somitos começa no final de E9,5 e início de E10,5, quando o intestino anterior e posterior tornam-se visíveis e o processo de desenvolvimento hepático se inicia, o que se dá pela conectividade da endoderme do intestino anterior com o desenvolvimento do coração (ELMAOUHOUB, 2006).

Por volta de E8, em camundongos, a parede ventral do endoderma do intestino anterior inicia seu desenvolvimento para uma destinação hepática, em resposta às ações indutivas de fatores de crescimento, no qual o FGF (fator de crescimento fibroblástico) é um deles, sendo este liberado pelo mesoderma cardíaco adjacente e pelas BMPs (proteínas morfogenéticas do osso) advindas do mesênquima do septo transverso (DUNCAN, 2003; BAHARVAN et al., 2006; CAI et al., 2007; ZORN, 2008). Aproximadamente em E9, as células da endoderma do intestino anterior já iniciaram a proliferação e diferenciação em hepatoblasto, levando a formação do broto hepático neste estágio (ZHAO \& DUNCAN, 2005; ZORN, 2008). Após a formação do broto hepático $(\mathrm{BH})$ e a migração dos hepatoblastos do intestino anterior para formar cordões em direção ao septo mesenquimal transverso, as células dentro do ambiente hepático embrionário se organizam para uma segunda diferenciação celular, gerando uma arquitetura hepática complexa (ZHAO \& DUNCAN, 2005).

Em ratos (Rattus norvegicus), o que se tem descrito quanto às características histológicas do desenvolvimento hepático é que o BH começa a se desenvolver com 10,5 dias de gestação. Nesse período, as células hematopoiéticas saem do fígado para suas destinações finais e o fígado inicia a organização de sua estrutura e desenvolve numerosas funções metabólicas, tornando-se maturo (ELMAOUHOUB, 2006). Embora o desenvolvimento embrionário de ratos e camundongos, principalmente o último, seja relativamente bem compreendido atualmente, as características histológicas hepáticas são ainda uma lacuna no conhecimento.

Sendo assim, o presente estudo teve como objetivo caracterizar histologicamente o processo de desenvolvimento hepático embrionário em ratos, visando futuros estudos.

\section{MATÉRIAL E MÉTODOS}

Animais

Para o estudo, foi utilizada a linhagem de ratos isogênicos Fischer 344, a qual apresenta vantagens experimentais sob outros ratos não isogênicos, como a histocompatibilidade e a uniformidade genotípica e fenotípica, reduzindo o número de animais no experimento, permitindo a repetibilidade dos experimentos (BAPTISTA et al., 2011). Essa linhagem tem sido utilizada principalmente em pesquisas envolvendo terapia celular e transplante autólogo (MIN et al., 2005; MURAOKA et al., 2006), devido às características já citadas.

Acasalamentos e obtenção dos embriões

Os acasalamentos das ratas isogênicas F344 para obtenção dos embriões em diferentes períodos gestacionais foram realizados após verificação do ciclo estral destas. Lavado vaginal com solução fisiológica $0,9 \%$ foi realizado na manhã seguinte à junção dos casais para verificação da presença de espermatozoides, em lâminas histológicas, com auxílio de microscópio de luz. Sendo contabilizado, quando da presença de espermatozoides no lavado vaginal, o dia embrionário 0,5 (E0,5). Cinco embriões de ratos F344 de cada período gestacional (E12,5; E13,5; E14,5; E15,5; e E16,5) foram coletados após eutanásia das ratas com a utilização de isofluorano por tempo prolongado.

Processamento das amostras

Os embriões coletados foram fixados em Metacarn (60\% metanol, 30\% clorofórmio e $10 \%$ ácido acético) por 12 horas. As amostras foram desidratas em uma série de etanóis em concentrações crescentes e diafanizados em xilol, seguido de inclusão (JUNQUEIRA \& CARNEIRO, 1994) em paraplast $^{\circledR}$ (Paraplast Embedding Media, Paraplast Plus, Sigma, Oxford Lab. USA). Foram realizados

Ciência Rural, v.43, n.6, jun, 2013. 
cortes seriados de $5 \mu \mathrm{m}$ de espessura, obtidos através de um micrótomo semi-automático (Leica, RM2165).

Colorações histológicas

Foram realizadas as seguintes colorações: Hematoxilina-eosina, tricômio de Masson (BANCROFT,1996), PAS (Periodic Acid Schiff) (BANCROFT, 1996) e picro sírius. As fotomicrografias foram realizadas por meio do software KS400 4.4, marca ZEISS. Utilizou-se o microscópio OLYMPUS (modelo BX60) e a câmera
AxioCam (Modelo HCr, marca ZEISS) para o procedimento.

\section{RESULTADOS E DISCUSSÃO}

Com E12,5 dias (Figura 1A), os embriões de rato Fischer 344 (F344) apresentaram BH em início de desenvolvimento. Nele, é possivel observar dois segmentos do $\mathrm{BH}$, precursor do figado adulto. Nesse período, o BH é constituído por células-tronco bipotenciais, os hepatoblastos, células capazes de

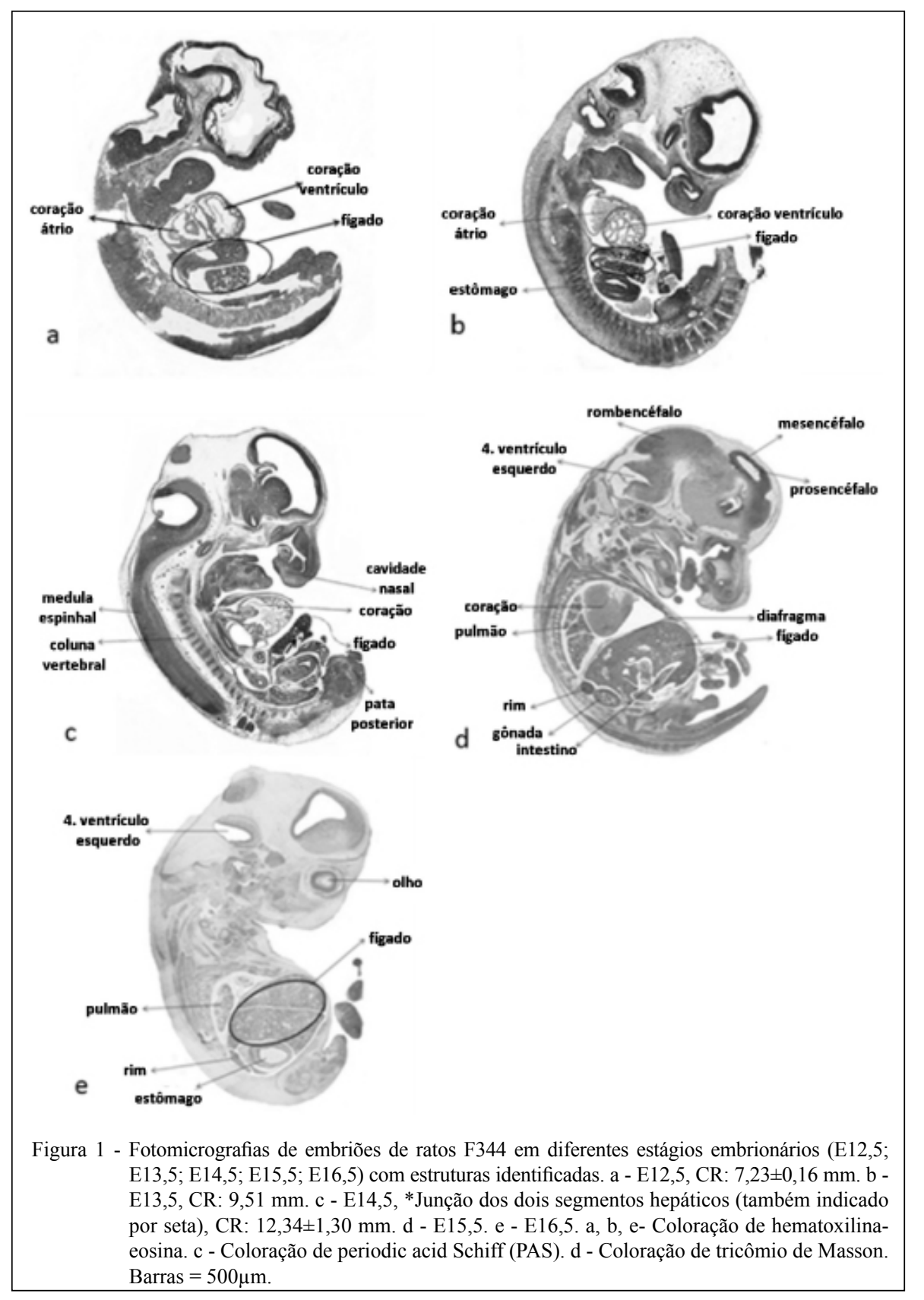

Ciência Rural, v.43, n.6, jun, 2013. 
extensiva proliferação (KIYOTA et al., 2007) e subsequente diferenciação em células do ducto biliar e hepatócitos (Figura 2A) (THONSON et al., 1998). Tais células apresentam núcleo grande basófilo e pouco citoplasma (Figura 2A, B), como descrito na literatura ( $\mathrm{OH}$ et al., 2005). O período com 13,5 dias (Figura 1B) distingue-se do anterior apenas pelo formato diferenciado dos hepatoblastos. Neste, essas células apresentaram-se mais fusiformes, característica possivelmente devido a eminente diferenciação em hepatócito (Figura 2B), fato esse também observado no cultivo celular (GUERRA et al., 2009).

Com E14,5 dias (Figura 1C), o BH apresenta quatro lobos hepáticos distintos, sendo possível evidenciar histologicamente hepatoblastos e hepatócitos concomitantemente, além de megacariócitos, células com núcleos multilobulados

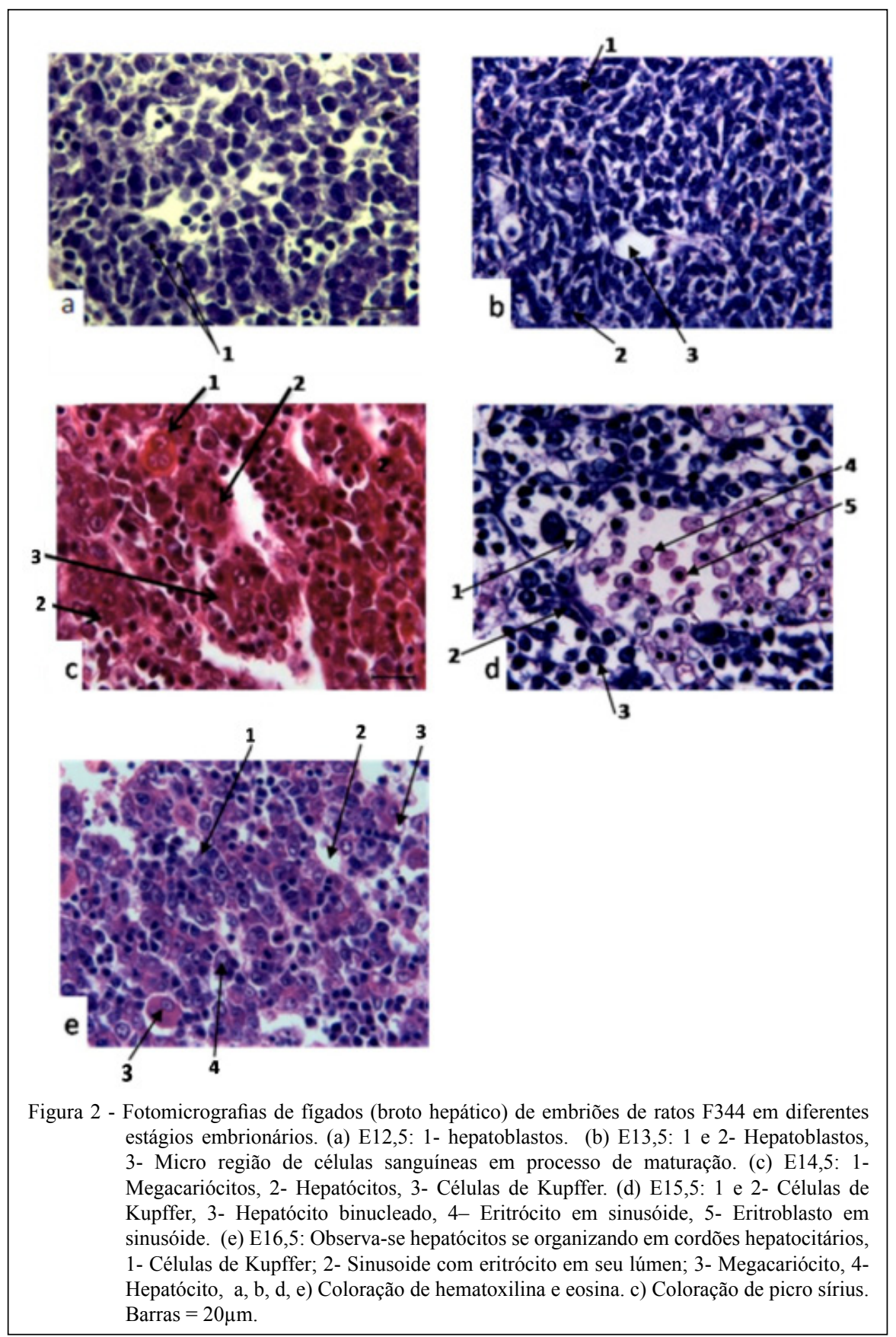

Ciência Rural, v.43, n.6, jun, 2013. 
precursoras das plaquetas. Nessa fase, células sanguíneas precursoras, ainda nucleadas, denominadas eritroblastos foram também observadas, uma vez que o fígado é o primeiro órgão hematopoiético depois do saco vitelino (Figura 2C), assumindo essa função até a formação da medula óssea (MOORE \& PERSAUD, 2008).

Em embriões com 15,5 e 16,5 dias (Figura $1 \mathrm{D}, \mathrm{E})$, fica notório o aumento de volume dos BHs nos embriões, os quais já possuem um aspecto morfológico semelhante a um fígado maduro, permitindo seu isolamento com maior facilidade, quando necessário experimentalmente, utilizando instrumentos microcirúrgicos (GUERRA et al., 2009). Entretanto, histologicamente, ele ainda não possui as mesmas características de um fígado maduro. Nos embriões com 15,5 dias (Figura 2D), verificou-se, assim como naqueles com 14,5, a coexistência de hepatoblastos e das células já diferenciadas, os hepatócitos. Em embriões com 15,6 dias, a arquitetura hepática começa a ser alterada com a formação de inúmeros sinusoides. Nesse prazo gestacional, também é possível observar dentro dos sinusoides células sanguíneas em diferentes estágios de maturação, além de células de Kupffer, aderidas principalmente à porção luminal das células endoteliais dos sinusóides (região perissinusoidal), sendo suas características morfológicas e posição em consonância com o encontrado na literatura (LOPEZ et al., 2011).

Com 16,5 dias (Figura 1E e 2E), a quantidade de hepatócitos é maior em detrimento de hepatoblastos, representando a grande maioria das células do órgão em maturação. Nesse prazo, é possível observar de forma nítida a formação dos cordões de hepatócitos que confluem para as veias centrolobulares, características de um fígado maduro, notório pela formação dos lóbulos hepáticos, unidade funcional hepática (JUNQUEIRA \& CARNEIRO, 2004). Ramos da veia porta também são observados, os quais fazem parte do espaço porta, que fica entre os lóbulos hepáticos (JUNQUEIRA \& CARNEIRO, 2004). Nesse prazo, o fígado possui função hematopoiética, uma vez que ainda são encontradas células da linhagem sanguínea em diferentes estágios de diferenciação no parênquima hepático. Como a diferenciação final da linhagem celular hepática, em camundogos, ocorre até os 17,5 dias (MCLIN $\&$ ZORN, 2006), é de se esperar que o processo de diferenciação final nos ratos ultrapasse tal prazo gestacional, visto o maior prazo gestacional (21 dias) em ratos (LADELLA et al., 2003).

\section{CONCLUSÃO}

Os resultados demonstram histologicamente, pela primeira vez, o desenvolvimento hepático de embriões de ratos entre 12,5-16,5 dias, evidenciando as células que compõem cada período gestacional. Os resultados apresentados poderão trazer subsídios para futuros estudos embrionários, hepáticos ou de terapia celular, utilizando-se esse promissor modelo animal.

\section{AGRADECIMENTO}

Este estudo teve o suporte da Faculdade de Medicina Veterinária e Zootecnia da Universidade de São Paulo (USP), Brasil, Departamento de Ciências Veterinárias da Universidade Federal da Paraíba (UFPB), Brasil, e Financiamento do Conselho Nacional de Desenvolvimento Científico e Tecnológico (CNPq) e Fundação de Amparo à Pesquisa do Estado de São Paulo (FAPESP).

\section{COMITÊ DE ÉTICA E BIOSSEGURANÇA}

Este trabalho foi aprovado pelo comitê de bioética da FMVZ/USP, protocolado sob o n. 1377/2008.

\section{REFERÊNCIAS}

BANCROFT, J.D.; STEVENS, A.S. Theory and practice of histological techniques. Edinburgh: Churchill Livingstone, 1996. 4v.

BAPTISTA, A.B. et al. Efeito da fotoperiodicidade na taxa de prenhez em ratos isogênicos (F344). Ciência Rural, v.41, p.171175, 2011. Disponível em: <http://dx.doi.org/10.1590/S0103$84782011000100028>$. Acesso em: 14 ago. 2012. doi: 10.1590/ S0103-84782011000100028.

CAI, J. et al. Directed differentiation of human embryonic stem cells into functional hepatic cells. Hepatology, v.45, p.12291239, 2007. Disponível em: <http://www.ncbi.nlm.nih.gov/ pubmed17464996>. Acesso em: 13 set. 2012. doi:10.1002/ hep. 21582 .

DUNCAN, S.A. Mechanisms controlling early development of the liver. Mechanism of development, v.120, p.1933, 2003. Disponível em: <http://www.ncbi.nlm.nih.gov/ pubmed/12490293>. Acesso em: 05 ago. 2012. doi: 10.1016/ S0925-4773(02)00328-3.

ELMAOUHOUB, L. Characterization of foetal hepatic cells during the liver development. 2006. 132f. Dissertation (Mathematisch naturwissenschaftliche Fakultäten) - Georg August Universität zu Göttingen.

GUERRA, R.R. et al. Isolation and characterization of stem cells committed to the liver lineage for bridge transplantation. In: CONGRESS OF THE INTERNATIONAL FEDERATION OF ASSOCIATIONS OF ANATOMISTS, 17., 2009, Cape Town. Anais... Cape Town: 17th Congress of the International Federation of Associations of Anatomists, 2009.

JUNQUEIRA, L.C.; CARNEIRO, J. Histologia básica. Rio de Janeiro: Guanabara Koogan, 2004. 10v. 
KIYOTA, A. et al. Induction and high density culture of human hepatoblasts from fetal hepatocytes with suppressing transformation. Biological \& pharmaceutical bulletin. v.30, p.2308-2311, 2007. Disponível em: <http://www.ncbi.nlm.nih. gov/pubmed/18057717>. Acesso em: 13 set. 2012. doi: 10.1248/ bpb.30.2308.

LADELLA, S.J. et al. Maternal plasma hypertonicity is accentuated in the postterm rat. American Journal of Obstetrics \& Gynecology, v.189, p.1438-1444, 2003. Disponível em: <http:// www.ncbi.nlm.nih.gov/pubmed/14634583>. Acesso em: 25 ago. 2012. doi: 10.1067/S0002-9378(03)00628-8.

LOPEZ, et al. Characterization of Kupffer cells in livers of developing mice. Comparative Hepatology, v.10, n.2, p.2-10, 2011. Disponível: <http://www.comparative-hepatology.com/ content/pdf/1476-5926-10-2.pdf>. Acesso em: 20 fev. 2013. doi: $10.1186 / 1476-5926-10-2$.

MCLIN, V.A.;ZORN,A.M. Molecular control of liver development. Clinics in Liver Disease, v.10, p.11-25, 2006. Disponível em: $<$ http://www.ncbi.nlm.nih.gov/pubmed/16376792>. Acesso em: 02 set. 2012. doi: 10.1016/j.cld.2005.10.002.

MIN, J.Y. et al. Stem cell therapy in the aging hearts of Fisher 344 rats: synergistic effects on myogenesis and angiogenesis. Journal of Thoracic and Cardiovascular Surgery, v.130, n.2, p.547-553, 2005. Disponível em: <http:/www.ncbi.nlm.nih.gov/ pubmed/16077426>. Acesso em: 01 out. 2012. doi: 10.1016/j. jtcvs.2005.03.017.

MOORE, K.L.; PERSAUD, T.V.N. Embriologia básica. Rio de Janeiro: Elsevier, 2008. 8v.

OH, S.K. et al. Derivation and characterization of new human embryonic stem cell lines: SNUhES1, SNUhES2, and SNUhES3. Stem Cells, v.23, p 211-219, 2005. Disponível em: <http://www. ncbi.nlm.nih.gov/pubmed/15671144>. Acesso em: 26 ago. 2012. doi: 10.1634/stemcells.2004-0122.
MURAOKA, et al. The high integration and differentiation potential of autologous neural stem cell transplantation compared with allogeneic transplantation in adult rat hippocampus. Experimental Neurology, v.199, n.2, p.311-327, 2006. Disponível em: <http://www.sciencedirect.com/science/article/pii/ S0014488605004541>. Acesso em: 20 fev. 2013. doi: 10.1016/j. expneurol.2005.12.004.

PASSOS, C.C. Função do fator de crescimento progranulina na diferenciação e proliferação de células de linhagem hepática, durante o desenvolvimento embrionário de ratos Fisher. 2010. 82f. Dissertação (Mestrado em Anatomia dos Animais Domésticos e Silvestres) - Faculdade de Medicina Veterinária e Zootecnia, Universidade de São Paulo, SP.

POUTON, C.W.; HAYNES, J.M. Pharmaceutical applications of embryonic stem cells. Advanced Drug Delivery Reviews, v.57, p.1918-1934, 2005. Disponivel em: <http://www.ncbi.nlm.nih. gov/pubmed/16290153>. Acesso em: 13 set. 2012. doi: 10.1016/j. addr.2005.08.003.

THONSON, J.A. et al. Embryonic stem cell lines derived from human blastocysts. Science, v.282, p.1145-1147, 1998. Disponível em: $\quad<$ http://www.sciencemag.org/content/282/5391/1145.full>. Acesso em: 13 set. 2012. doi: 10.1126/science.282.5391.1145.

ZARET, K.S. Regulatory phases of early liver development: paradigms of organogenesis. National Reviews Genetic, v.3, p.499-512, 2002. Disponível em: <http://www.ncbi.nlm.nih.gov/ pubmed/12094228>. Acesso em: 15 ago. 2012. doi: 10.1038/ nrg837.

ZHAO, R.; DUNCAN, S.A. Embryonic development of the liver. Hepatology, v.41, p.956-967, 2005. Disponível em: <http:// onlinelibrary.wiley.com/doi/10.1002/hep.20691/pdf>. Acesso em: 20 ago. 2012. doi: 10.1002/hep.20691.

ZORN, A.M. Liver development: stemBook. Cambridge: The Stem Cell Research Community, 2008. Disponível: $<$ http://www. stembook.org/node/512>. Acesso em: 16 ago. 2012. doi/10.3824/ stembook.1.25.1.

Ciência Rural, v.43, n.6, jun, 2013. 